03,09

\title{
Влияние электрического поля на водородоподобные состояния в кристаллах моноклинного дифосфида цинка
}

\author{
() И.Г. Стамов, Д.В. Ткаченко \\ Приднестровский государственный университет, \\ Тирасполь, Молдова \\ E-mail: istamov51@mail.ru
}

Поступила в Редакцию 8 сентября 2021 г.

В окончательной редакции 8 сентября 2021 г.

Принята к публикации 27 сентября 2021 г.

Исследовано влияние электрического поля на водородоподобные состояния в $\beta-\mathrm{ZnP} 2$. Установлено, что экситонные состояния $C_{n=1}$ в электрическом поле барьера Шоттки испытывают аномальный штарковский сдвиг, а состояния образующие обратную водородоподобную серию линий поглощений (ОВС), к электрическому полю практически не чувствительны. Определены закономерности поведения „возгораемого“ в электрическом поле экситонного $X_{n=2}$ состояния в $\beta-\mathrm{ZnP}_{2}$.

Ключевые слова: барьер Шоттки, водородоподобные состяния, аномальный эффект Штарка, экситон.

DOI: 10.21883/FTT.2022.01.51834.200

\section{1. Введение}

$\mathrm{B}$ спектрах поглощения кристаллов $\beta-\mathrm{ZnP}_{2}$ обнаружены и достаточно полно исследованы экситоны Ванье-Мотта, которые благодаря низкой симметрии кристалла и снятию вырождения кристаллическим полем представлены несколькими сериями дипольноразрешенных и дипольно-запрещенных оптических переходов [1-3]. В кристаллах $\beta-\mathrm{ZnP}_{2} \quad n$-типа проводимости, кроме этого, проявляется тонкая структура водородоподобных состояний с достаточно большой силой осциллятора, расположенная с длинноволновой области спектра экситонов в интервале длин волн $\sim 20 \mathrm{~nm}$ [4-6]. Наиболее интенсивные линии этой серии образуют обратную водородоподобную серию (ОВС), которую в работах [4-5] связывают с биэлектроннопримесным комплексом (БПК), в работе [6] с экситонами, связанными на дефектами кристаллической решетки. Экспериментальное обнаружение серии линий ОВС в $\mathrm{BiI}_{3}$ [7], инициировало появление теоретических работ, в которых обсуждается возможность биэлектронного (бихоловского) взаимодействия в кристаллах [8-10], а также проявления фотоиндуцированной сверхпроводимости [11]. Возможность возбуждения электронов в зону проводимости с отрицательной инертной массой показана в работе [12]. Характер действия электрического поля на водородоподобные состояния в области спектра проявления ОВС является важным с точки зрения построения модели таких взаимодействий. Исследование экситонных синглетных и триплетных состояний в электрическом поле также представляет определенный интерес в связи с аномальным поведением штарковских сдвигов экситонных состояний, обнаруженных на $A_{n=1}$ состоянии в $\mathrm{CdS}$ [13]. Штарковский сдвиг, в соответствии с результатами этой работы, испыты- вает существенные отклонения от квадратичного (по электрическому полю) закона и в предионизационном поле изменяет знак. Теоретические основы для такого эффекта для атома водорода в электрическом поле, представлены в [14].

Влияние электрического поля на экситонные состояния $C_{n=1}-$ серии водородоподобных состояний в $\beta-\mathrm{ZnP}{ }_{2}$ исследовано в работе [15]. В электрическом поле, по мере его увеличения, наблюдается длинноволновый сдвиг экситонного контура и приобретение им антидисперсионного вида в предельных электрических полях. Более детальные исследования показали, что кристаллы, в которых экситонные спектры проявляются без тонкой структуры, имеют дырочный тип проводимости, с тонкой структурой и ОВС в спектрах, электронный [16]. Для кристаллов с дырочным типом проводимости в тонких слоях характерен механизм протекания тока ограниченный объемным зарядом, при котором напряженность электрического поля практически линейно возрастает от нуля на аноде до максимальных значений на катоде. Причем, в области катода величина и распределение электрического поля зависят от подсветки зондирующим и фоновым излучением. Нужное по величине электрическое поле для исследования экситонных состояний на „толстых“ кристаллах сложно создать из-за предельно больших значений напряжений полного заполнения ловушек. Исследование экситонных состояний $\beta-\mathrm{ZnP} \mathrm{P}_{2}$ в электрическом поле барьера Шоттки по спектрам отражения также затруднено из-за частичного наложения спектров экситонного поглощения и спектров ОВС.

В настоящей работе представлены результаты исследований водородоподобных состояний в области края поглощения $\beta-\mathrm{ZnP}_{2}$ в электрическом поле барьера Шоттки. Исследования проведены на структурах ITO- $\beta-\mathrm{ZnP}{ }_{2}$ по 
спектральному распределению фототока при температуре $80 \mathrm{~K}$. Основные характеристики таких структур, в том числе и при низких температурах представлены в работах $[16,17]$.

\section{2. Результаты и обсуждение}

На рис. 1 представлены спектральные характеристики фототока структуры ITO- $\beta-\mathrm{ZnP}_{2}$ при обратном смещении на барьере в поляризации $\mathbf{E} \| \mathbf{c}$ при падении нормальном падении излучения на плоскость (010).

Величина фототока в барьерах Шоттки в случае, когда толщина слоя пространственного заряда (ОПЗ) W много меньше толщины кристалла $L$ и выполняется условие $\alpha W \ll 1$, описывается выражением [18]:

$$
I_{\mathrm{ph}} \propto(1-R) \alpha \frac{(L+W)}{\left(1+\alpha L_{p}\right)},
$$

где $R$ - коэффициент отражения света, $W$ - ширина области пространственного заряда, $\alpha-$ коэффициент поглощения света.

Выражение (1) для фототока получено без учета влияния поверхностных электронных состояний контакта. Здесь также не учитывается влияние на коэффициент поглощения электрического поля. Контуры линий фототока резонансных состояний отражают спектральное распределение коэффициента поглощения, так как фототок пропорционален коэффициенту поглощения, а ширина ОПЗ и напряженность электрического поля, от приложенного напряжения. В этом случае становится возможным измерение энергетических характеристик линий поглощения от напряженности электрического поля барьера. В дифосфиде цинка, в области края фундаментального поглощения, коэффициент поглощения света $\alpha$ в максимумах линий экситонных переходов В-серии не превышают $780 \mathrm{~cm}^{-1}$ соответственно [2], на наиболее интенсивных линиях БПК $-75 \mathrm{~cm}^{-1}$ [9] в поляризации $\mathbf{E} \|$ с. При ширинах ОПЗ $\sim 1 \mu \mathrm{m}$, приведенные выше условия выполняются достаточно хорошо. Напряженность электрического поля барьера от приложенного напряжения определяется следующей зависимостью [16]:

$$
F_{m}^{2}=\varepsilon \varepsilon_{0} \frac{2\left(\varphi_{k}-\varphi_{d}-U\right)}{q N_{d}}
$$

где: $N_{d}-$ концентрация ионизированных доноров в ОПЗ барьера, $\varphi_{k}$ - высота потенциального барьера, $\varphi_{d}$ - глубина залегания донора, $\varepsilon-$ относительная диэлектрическая проницаемость полупроводника. Из этого выражения следует, что при отсутствии внешнего смещения барьера напряженность электрического поля на границе ОПЗ с металлом достигает значительных величин $\left(\sim 10^{4} \mathrm{~V} / \mathrm{cm}\right)$.

Контуры линий фототока резонансных состояний отражают спектральное распределение коэффициента поглощения в $\beta-\mathrm{ZnP}_{2}$ и значительно уширены. Величина

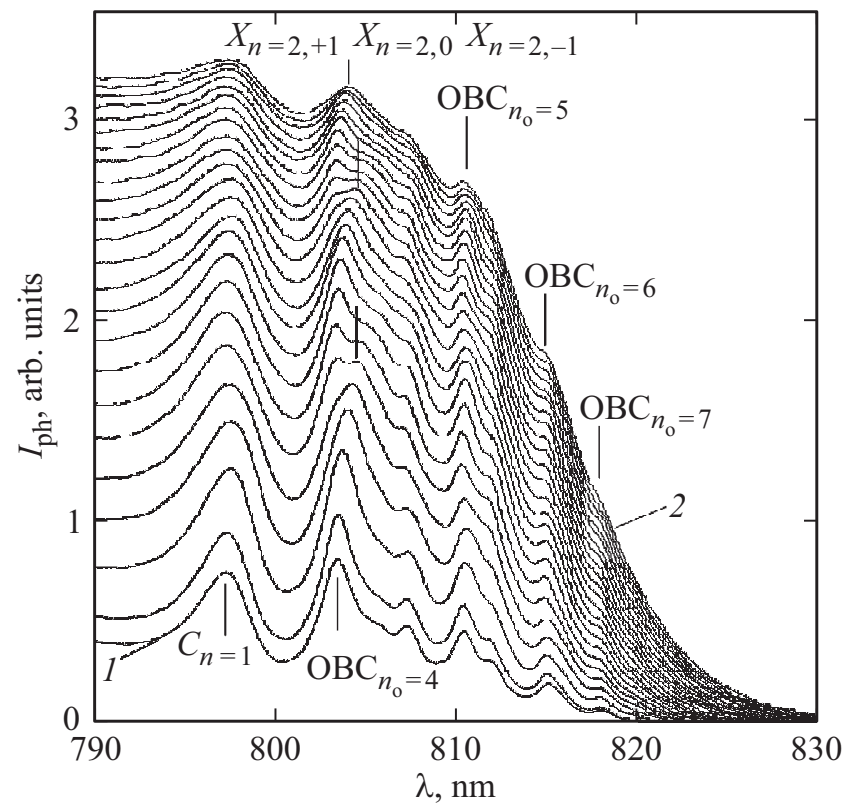

Рис. 1. Спектральные зависимости фототока при обратном смещении барьера Шоттки, $U, \mathrm{~V}: 1-0,2-4.2$ (интервал между спектральными зависимостями $-0.2 \mathrm{~V})$.

фототока сглаживается из-за изменения глубины генерации неравновесных носителей заряда при изменении коэффициента поглощения. Следствием этого является размытие спектра фототока при относительно небольших обратных смещениях и слабая зависимость величины фототока в спектральных областях с большими коэффициентами поглощения и при больших обратных напряжениях. Полоса фототока, соответствующая синглетному состоянию $C_{n=1}$ - экситона во всех исследуемых структурах в относительно слабых электрических полях до $\sim 2 \cdot 10^{2} \mathrm{~V} / \mathrm{cm}$ испытывают уширение и сдвиг в длинноволновую область спектра (рис. 2). При больших полях, поведение этой полосы аналогично поведению $1 \mathrm{~s}$ состоянию экситона в $\mathrm{CdS}$ [12], с ростом поля происходит сдвиг максимума в коротковолновую область. В нашем случае при дальнейшем увеличении напряжения и росте электрического поля в барьере, эффект последовательного длинноволнового и коротковолнового смещения максимума фототока повторяется. Такой эффект предсказывается в теоретической работе [14]. Кроме того, с ростом напряженности поля в барьере растет коротковолновое крыло полосы фототока за счет перекрытия полосы с зонным поглощением, край которого смещается в длинноволновую область из-за зонного эффекта Франца-Келдыша.

При напряжениях $|U| \geq-0.6 \mathrm{~V}$ и соответствующих им напряженностях электрического поля в спектральной области полосы $\mathrm{OBC}_{n_{0}=4}$ наблюдаются полосы с разными спектральными и амплитудными сдвигами, зависящими от приложенного напряжения с характерным для квадратичного эффекта Штарка поведением 


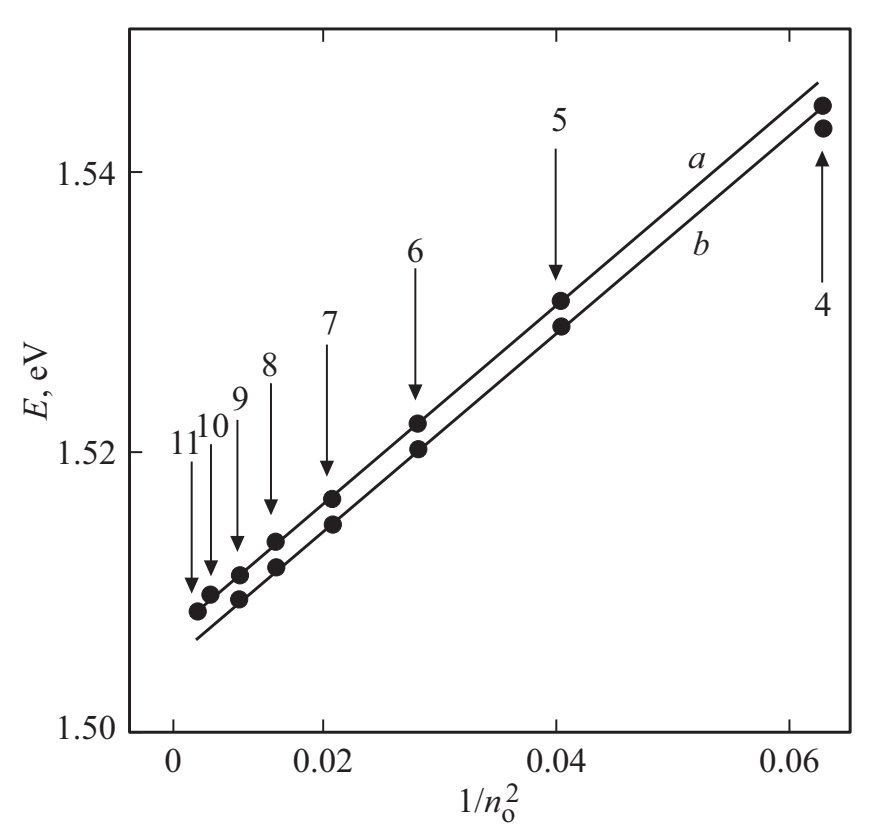

Рис. 2. Зависимость энергий переходов ОВС от $1 / n_{\mathrm{o}}^{2}$ для двух структур ITO-ZnP $2\left(C_{2 h}^{5}\right)$ (построена по спектрам пропускания кристаллов). Концентрация свободных носителей заряда в структурах № 3 и № 4: $\left.a)-10^{20} \mathrm{~m}^{-3}, b\right)-10^{21} \mathrm{~m}^{3}$.

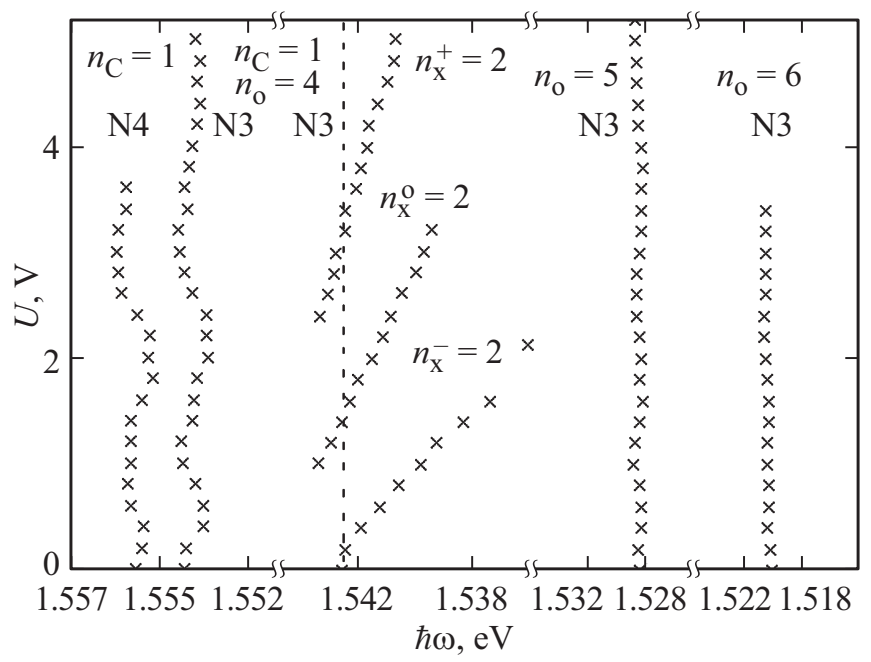

Рис. 3. Полевые зависимости экситонных состояний и экстремумов ОВС.

(рис. 3, полосы $X_{n=2}^{+}, X_{n=2}^{\text {o }}, X_{n=2}^{-}$). При экстраполяции к нулевому полю максимумы этих полос сходятся к энергии $1.547 \mathrm{eV}$, что не совпадает с энергий полосы $\mathrm{OBC}_{n_{0}=4}(1.544 \mathrm{eV})$ и энергиями экситонных состояний в спектрах поглощения в отсутствии поля [2,3]. Ближайшему экситонному состоянию соответствует энергия $B_{n=1}$. Как показано в работе [2], В-серия обусловлена $n S$ - состояниями ортоэкситона, отщепленного короткодействующим обменным взаимодействием. Состояние $B_{n=1}$ в спектрах фототока в спектрах фототока не наблюдается из-за полосы $C_{n=1}$ большей интенсивности в поляризациях $\mathbf{E} \| \mathbf{c}$ и $\mathbf{E} \perp \mathbf{c} . \mathrm{B}$ поляризации $\mathbf{E} \perp \mathbf{c}$, в электрическом поле, по-видимому, частично снимается запрет на переходы в синглетное $C_{n=1}$ состояние экситона. В фотоэффектах коэффициент фотоплеохроизма, определяемого по общепринятым формулам [19], меньше на много порядков коэффициента плеохроизма, определяемого по поглощению. Энергия наблюдаемого возбуждения отстоит от $C_{n=1}$ и $B_{n=1}$ на 12 и $10 \mathrm{meV}$. Коэффициенты в полевых зависимостях энергий полос для расщепленных в электрическом поле состояний $X_{n=2}^{+}, X_{n=2}^{\mathrm{o}}, X^{-}$составляют - $(0.47,0.82,2.19) \cdot 10^{-17} \mathrm{meV} \cdot \mu \mathrm{m}^{2} / \mathrm{V}^{2}$ соответственно. При напряжениях на барьере $|U| \leq-0.6 \mathrm{~V}$ эти полосы $X_{n=+2}, X_{n=0}, X_{n=-2}$ не проявляются из-за большей по интенсивности полосы $\mathrm{OBC}_{n_{0}=4}$, положение и интенсивность которой не изменяется при изменении напряженности электрического поля. В спектрах, представленных в [2], при температурах $2 \mathrm{~K}$, в названных авторами статьи „грязных“ кристаллах, $X$ - линия обнаруживается с длинноволновой стороны $B_{n=1}-$ линии поглощения. Однако природа этой полосы поглощения связывается с дефектами в кристаллах и не обсуждается. Можно предположить, что полосы $X$ связаны с возбужденным состоянием связанного экситона на дефектах решетки, основное состояние которого находится в области поглощения ОВС.

Полосы $n_{\mathrm{o}}=4-8$, которые проявляются в этих спектрах, укладываются в обратную водородоподобную сериальную зависимость, отмеченную в [4] (рис. 2). Полевые сдвиги максимумов этих полос не превышают пределов погрешностей их определения. Перегибы при полосах $n_{\mathrm{o}}=4$ и 5 следует отнести к положительным водородоподобным сериям линий поглощения (ПВС), имеющим место при каждой линии ОВС [1]. Следствием экранирования является сдвиг всего спектра экситонных состояний кристаллов с отличающимися концентрациями носителей заряда, причем состояния $C_{n=1}-$ серии экситонов смещены на $1.4 \mathrm{meV}, \mathrm{OBC}$ на $2.2 \mathrm{meV}$.

$X$ - линия экситона, ее расщепленные состояния в электрическом поле и линии ОВС проявляются в поляризациях $\mathbf{E} \| \mathbf{c}$ и в поляризации $\mathbf{E} \perp \mathbf{c}$. В поляризации $\mathbf{E} \perp \mathbf{c}$ интенсивность линий фототока всего спектра меньше, чем в поляризации $\mathbf{E} \| \mathbf{c}$. Поведение экситонных состояний и состояний БПК-комплекса в поляризациях $\mathbf{E} \perp \mathbf{c}$ и $\mathbf{E} \| \mathbf{c}$ имеют подобный характер, однако спектры фототока сдвинуты относительно друг друга на величину $0.2 \mathrm{meV}$.

Корреляции с указанными выше закономерностями поведения в электрическом поле полос фототока наблюдаются в спектрах отражения в электрическом поле барьера (рис. 4).

Особенности в спектрах отражения при длинах волн $\lambda>800 \mathrm{~nm}$ связаны с резонансами ОВС, при длинах волн $\lambda<800 \mathrm{~nm}-$ состоянием $C_{n=1}$ экситона. На контур отражения $C_{n=1}$ экситона накладывается отражение контура $\mathrm{OBC}_{n_{0}=4}$. При положительных напряжениях на 


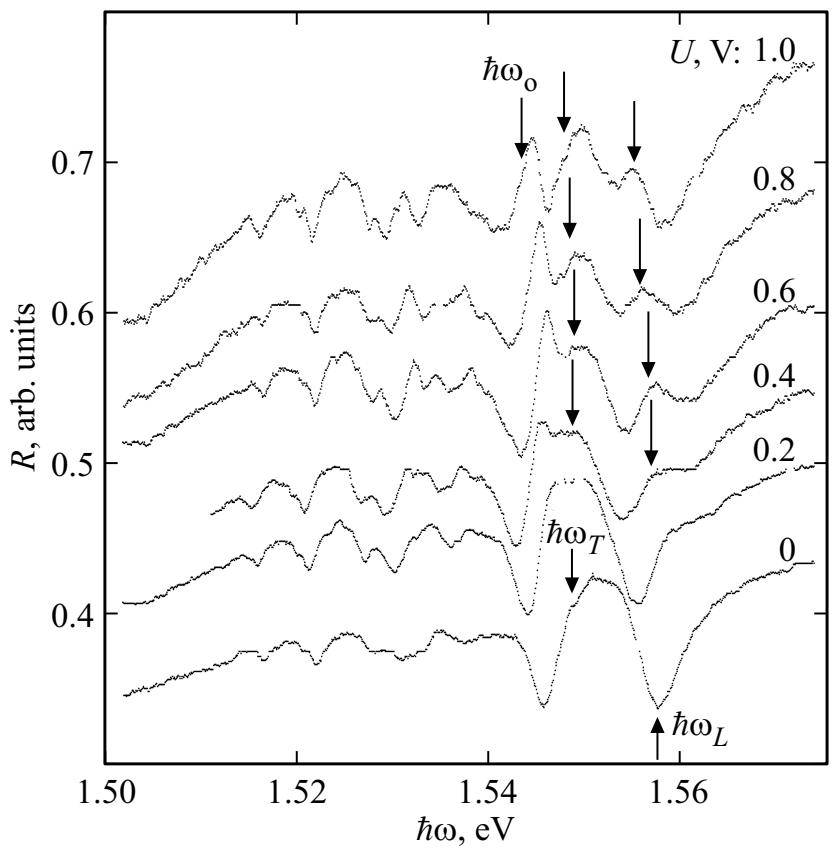

Рис. 4. Относительные спектры экситонного отражения в зависимости от энергии фотонов при различных значениях приложенного к структуре ITO-ZnP 2 обратного напряжения $(80 \mathrm{~K})$.

барьере форма спектров изменяется незначительно, происходит сдвиг $\hbar \omega_{L}$ в коротковолновую область спектра на $0.2 \mathrm{meV}$. При напряжениях $U>0.4 \mathrm{~V}$ на энергии $\hbar \omega_{L}$ проявляется спайковая структура, рост которой с увеличением напряжения и электрического поля барьера преобразует контур отражения в антидисперсионный вид. С ростом напряженности поля барьера наблюдается цикличность изменения формы спектров отражения, связанная с наличием „мертвого“ слоя. При больших обратных напряжениях особенности в спектрах размываются, что связано с диссоциацией состояний и наложением отражений состояний с разными полевыми коэффициентами. Математическое описание спектров в многоосциляторной модели представляется проблематичным с учетом большего числа переменных и отсутствия данных по полевой диссоциации составляющих спектра.

Весь спектр частот резонансов фототока и соответствующие им значения в спектрах отражения при одинаковых приложенных смещениях барьера сдвинуты относительно друг друга на величину $2.7 \mathrm{meV}$, что может быть связано с тем, что спектры отражения сняты при максимальном значении электрического поля на границе контакта, а спектры фототока, при некотором „среднем“ поле.

\section{3. Заключение}

B спектрах фототока структур ITO-ZnP $2\left(C_{2 h}^{5}\right)$ проявляются основные особенности поглощения света в моноклинном дифосфиде цинка при низких температурах. Синглетные состояния в электрическом поле испытывают аномальный сдвиг, впервые обнаруженный в [11] и характерный для атомных спектров водорода в электрическом поле. Обнаруженные осцилляции в смещении положения $C_{n=1}$ синглетного экситона в поле барьера согласуются с теорией для атома водорода в электрическом поле. В электрическом поле барьера Шоттки происходит „возгорание“ экситона $X_{n=2}$, его интенсивность возрастает до уровня поглощения света самой интенсивной линии в ОВС и расщепляется в соответствии в представлениями о водородоподобных состояниях. Смещение линии в полях $\left(10^{4}-10^{6}\right) \mathrm{V} / \mathrm{cm}$ удовлетворяет квадратичному эффекту Штарка. Природа этой полосы поглощения не известна и для ее определения необходимы дополнительные исследования. Состояния образующие ОВС ведут себя как одно целое электрическое поле не оказывает заметного действия на их энергетическое положение в спектрах. Водородоподобное взаимодействие квазичастиц образующих ОВС с ионизированными донорами размываются в электрическом поле из-за малой энергии связи, что в целом может быть свидетельством в пользу модели предложенной в [5]. Важным следствием из представленных исследований является подтверждение теоретического анализа и аргументации наблюдаемых в эксперименте серий экситонных состояний в $\mathrm{ZnP}_{2}$ представленных в ряде работ [1-5].

\section{Конфликт интересов}

Авторы заявляют, что у них нет конфликта интересов.

\section{Список литературы}

[1] А.Б. Певцов, С.А. Пермогоров, А.В. Селькин, Н.Н. Сырбу, А.Г. Уманец. ФТП 16, 8, 1399 (1982).

[2] И.С. Горбань, А.П. Крохмаль, 3.3. Янчук. ФТТ 42, 1582 (2000).

[3] I.G. Stamov, A.V. Dorogan, N.N. Syrbu, V.V. Zalamai. Am. J. Mater. Sci. Appl. 2, 96 (2014).

[4] Н.Н. Сырбу, И.Г. Стамов, С.И. Радауцан. Докл. АН СССР 262, 5, 1138 (1982)

[5] А.В. Селькин, И.Г. Стамов, Н.Н. Сырбу, А.Г. Уманец. Письма в ЖЭТФ 35, 2, 51 (1982).

[6] В.В. Соболев, А.И. Козлов, И.И. Тычина, П.А. Романик, Э.М. Смоляренко. Письма в ЖЭТФ 34, 3, 115(1981).

[7] Е.Ф. Гросс, В.И. Перель, Р.И. Шехмаметьев. Письма в ЖЭТФ 13, 320 (1971).

[8] В.А. Коварский, Э.П. Синявский, В.Н. Чеботарь, Л.П. Черныш. ФТП 18, 9, 1637 (1984).

[9] V.A. Kovarskii, E.P. Sinyavskii, L.V. Chernysh. Phys. Status Solidi B 123, 671 (1984).

[10] Э.П. Синявский, Н.Н. Сырбу, В.Н. Чеботарь. ФТП 20, 9 , 1481 (1986).

[11] В.А. Коварский, А.А. Голуб. ФТТ 16, 2, 817 (1974). 
[12] W. Kuehn, P. Gaal, K. Reimann, M. Woerner, T. Elsaesser, R. Hey. Phys. Rev. Lett. 104, 146602 (2010). DOI: 10.1103/PhysRevLett.104.146602.

[13] А.Б. Новиков, Б.В. Новиков, Г. Роппишер, А.В. Селькин, Н. Штайн, Р.Б. Юферев. ФТТ 40, 5, 879 (1998).

[14] R.J. Damburg, V.V. Kolosov. J. Phys. B 9, 18, 87 (1976).

[15] С.О. Романовский, А.В. Селькин, И.Г. Стамов, Н.А. Феоктистов. ФТТ 40, 5, 884 (1998).

[16] И.Г. Стамов, Д.В. Ткаченко. ФТП 42, 6, 679 (2008).

[17] И.Г. Стамов, Д.В. Ткаченко. Вестн. ПГУ 3, 32, 14 (2008).

[18] И. Аут, Д. Генцов, К. Герман. Фотоэлектрические явления. Мир, М. (1980). 208 с.

[19] Ю.В. Рудь. Изв. вузов СССР. Физика ХХІХ, 8, 68 (1986).

Редактор Т.Н. Василевская 